\title{
A NECESSIDADE DO ENSINO DO PROFISSIONALISMO TEACHING PROFESSIONALISM
}

Caríssimo Sr. Editor da Revista Portuguesa de Medicina GERAL E FAMILIAR (RPMGF),

Li com muito interesse e entusiasmo o editorial do volume 35 da RPMGF, da autoria da colega Raquel Braga, ${ }^{1}$ partilhando as suas preocupações relativamente à necessidade do ensino do profissionalismo quer em contexto pré-graduado, quer pós-graduado. Saliento, no editorial, a importância da necessidade de um ensino que utilize modelos de profissionalismo que potenciem a aquisição de competências, entendidas como um conjunto de conhecimentos, aptidões e atitudes, pelos alunos ou internos de medicina.

Gostaria de acrescentar algumas ideias que poderão ser úteis na reflexão sobre esta temática.

O desempenho médico de excelência é caracterizado por critérios que foram definidos quando, nos anos 80 do século XX, surgiu o conceito de profissionalismo como movimento ético no contexto académico norte-americano. ${ }^{2}$ Em 2002, e na consolidação desse movimento, a American Board of Internal Medicine Foundation, em conjunto com outras instituições, publica o documento Medical Professionalism in the New Millennium: A Physician Charter, ${ }^{3}$ definindo três princípios fundamentais do profissionalismo - o bem-estar do doente, a sua autonomia e a justiça social. Este documento espelha a evolução do conceito de profissionalismo e o seu vínculo direto às mudanças da relação médico-utente e ao papel do médico na sociedade.

Um modelo de profissionalismo assente na tradição do juramento Hipocrático é claramente insuficiente para dar uma resposta adequada aos conflitos éticos que surgem na relação assistencial diária. Este modelo surge no contexto de uma relação médico-utente paternalista, ${ }^{4}$ que evidencia o poder do médico e a dependência do utente e que coloca a beneficência no centro da decisão ética.

As mudanças de valores culturais da sociedade e as consequentes alterações na relação médico-utente impelem o nascimento de um Novo Profissionalismo que, mais do que centrado no paternalismo médico ou na autonomia do utente, implica o estabelecimento de uma relação deliberativa. ${ }^{5}$ Esta relação deliberativa estabelece-se quando, no encontro de valores de médico e utente, surge uma decisão que respeita o máximo de valores dos dois intervenientes.

As semelhanças entre o Novo Profissionalismo e a bioética são várias e frequentemente surgem como conceitos mesclados. No entanto, a sua clarificação é importante para responder à pergunta: será o ensino do profissionalismo suficiente para dar resposta ao dever de excelência do médico?

O profissionalismo é um conceito que nasce da reflexão dos profissionais de saúde em resposta aos desafios crescentes do desempenho da profissão. Em suma, trata-se de um contrato que a medicina estabelece com a sociedade, ${ }^{3}$ surgindo do interior da profissão para o exterior. Embora, os objetivos sejam claramente de benefício do utente e da sociedade, o profissionalismo poderá ser associado a questões problemáticas como o elitismo e a manutenção do poder. ${ }^{6}$

A bioética, disciplina que se traduz na aplicação da ética às questões da vida e da medicina, nasce por imperativo de uma realidade social que necessitava de respostas multidisciplinares, numa sociedade moralmente pluralista. ${ }^{7}$ De forma simples, tem origem na sociedade e invade a relação assistencial, num movimento centrífugo.

Podemos dizer que o Novo Profissionalismo tem as suas origens nos fundamentos da bioética, não esvaziando a totalidade dos seus conteúdos; por outro lado, a bioética não pode converter-se ou reduzir-se à ética profissional. ${ }^{8}$

Em conclusão, o ensino da bioética em contexto pré e pós-graduado, preferencialmente integrando o curriculum formal, é essencial para a excelência do desempenho profissional no contexto de uma sociedade e das suas instituições em evolução. Potter, citado por Daniel Serrão, ${ }^{9}$ considera que a bioética, como nova disciplina do pensamento humano, constitui uma estratégia de sobrevivência. A apreensão desta estratégia de sobrevivência dotará os futuros profissionais de competências que lhes permitirão afrontar os obstáculos crescentes ao profissionalismo, incluindo a pressão assistencial, a utilização de tecnologias de informação e as relações profissionais, institucionais e interinstitucionais. 
Finalmente, a utilização de metodologias de ensino que promovam a deliberação ética, possibilitarão aos alunos/internos e futuros profissionais de saúde a aquisição de competências na resolução de problemas éticos, problemas de conflitos de valores que surjam no contexto assistencial.

Ivone Gonçalves Gaspar*

* Médica de Família.

USF Dafundo, ACES Lisboa Ocidental e Oeiras.

Comissão de Ética ARSLVT.

Faculdade de Medicina da Universidade de Lisboa.

\section{REFERÊNCIAS BIBLIOGRÁFICAS}

1. Braga R. A necessidade do ensino do profissionalismo. Rev Port Med Geral Fam. 2019;35(4):258-60.

2. Borrell-Carrio F, Epstein RM, Pardell-Alentà H. Profesionalidad y professionalism: fundamentos, contenidos, praxis y docencia. Med Clin. 2006;127(9):337-42.

3. ABIM Foundation, American Board of Internal Medicine, ACP-ASIM Foundation, American College of Physicians, American Society of Internal Medicine, European Federation of Internal Medicine. Medical professionalism in the new millennium: a physician charter. Ann Intern Med. 2002;136(3):243-6.

4. Siegler M. Las tres edades de la medicina y la relación médico-paciente. Barcelona: Fundació Víctor Grífols i Lucas; 2011. ISBN 9788469431832

5. Gracia D. Values and bioethics. In: Serna-Bermúdez P, Seoane JA, editors. Bioethical decision making and argumentation. Springer; 2016. p. 17-29. ISBN 9783319434193

6. Salloch S. Same same but different: why we should care about the distinction between professionalism and ethics. BMC Med Ethics. 2016;17(1):44.

7. Cortina A. Hasta un pueblo de demonios: ética pública y sociedad. Taurus Ediciones; 1998. ISBN 9788430602988

8. Couceiro-Vidal A. Enseñanza de la bioética y planes de estudios basados en competencias [Teaching bioethics in outcome-based curricula]. Educ Med. 2008;11(2):69-76. Spanish

9. Serrão D. Comissões de ética: o desafio metodológico [Ethics commissions: the methodology challenge]. Nascer Crescer. 2008;17(4): 249-52. Portuguese

\section{RESPOSTA DA AUTORA DO EDITORIAL}

\section{"A necessidade do ensino do profissionalismo" [Rev Port Med Geral Fam. 2019;35(4):258-60] e do EDITOR-CHEFE DA REVISTA, SOB A FORMA DE COMENTÁRIO}

A Carta ao Editor, designação que se dá na Revista Portuguesa de Medicina Geral e Familiar (RPMGF) a esta tipologia de artigo, em vez de Carta ao Diretor, é o es- paço reservado na RPMGF para os leitores emitirem as suas observações, geralmente na forma de críticas ou de pedidos de esclarecimento, relativamente a artigos publicados previamente na revista.

Neste caso, não se trata propriamente de um contraditório, já que tanto a autora do Editorial, a colega Dra. Raquel Braga, como o Editor-chefe da Revista concordam em absoluto e agradecem os comentários da colega Dra. Ivone Gonçalves Gaspar, tão bem escritos e com uma robusta visão bioética, e que vêm acrescentar ao editorial informação válida e conceitos relevantes.

Para concluir estas breves palavras, salienta-se algum do pensamento já publicado na Revista sobre este assunto [Hespanhol A. Assegurar qualidade em medicina geral e familiar. Rev Port Clin Geral. 2004;20(2): 264-8], deixando ao leitor alguns excertos desse artigo como ponto de partida para a sua reflexão sobre este assunto:

"Uma das abordagens para definir «um bom médico» apoia-se nas capacidades técnicas de um cientista aplicado, ou seja que um «bom médico» combina os conhecimentos clínicos individuais com a melhor evidência externa disponível.

Outra abordagem para definir «um bom médico» apoia-se nas capacidades interpessoais dos médicos, $e$ que segundo o General Medical Council, do Reino Unido, citado por Hurwitz, compreendem a vocação e as qualidades pessoais do médico, bem como a exatidão $e$ uma mente ponderada, aberta à verificação e à aprendizagem através dos erros.

Um «bom médico» será portanto aquele que consegue unir as técnicas e as sensibilidades do cientista aplicado às capacidades reflexivas do humanista médico" (p. 264).

\section{Raquel Braga* Alberto Pinto Hespanhol**}

\footnotetext{
*Médica de Família. USF Lagoa, ULS Matosinhos.

**Departamento de Medicina da Comunidade, Informação e Decisão em Saúde.

CINTESIS - Centro de Investigação em Tecnologias e Serviços de Saúde.

Faculdade de Medicina da Universidade do Porto.

Editor-chefe da Revista Portuguesa de Medicina Geral e Familiar.
}

Enviado em 14-11-2019

Aceite em 02-12-2019 